\title{
Peningkatan Faktor Penuaan Arester Tanpa Sela Isolasi Polymer Akibat Kontaminan Kalsium Karbonat
}

\author{
Novizon*, Nofriadi, Dano Yustasia \\ Jurusan Teknik Elektro, Fakultas Teknik, Universitas Andalas, Sumatera Barat, Indonesia \\ *Corresponding author, e-mail: novizon@eng.unand.ac.id
}

\begin{abstract}
Abstrak - Arus bocor arester tanpa sela dapat digunakan sebagai indikator untuk menentukan tingkat penuaan arester. Arus bocor dipengaruhi oleh kontaminan yang ada pada isolasi arester. Paper ini menganalisa pengaruh kontaminasi terhadap arus bocor arester sebagi indikator penuaan arester. Kontaminan yang digunakan adalah kalsium karbonat di tambah kaolin yang di larutkan kedalam air, untuk menentukan tingkat kontaminan kalsium karbonat maka digunakan metode ESDD (Equivalent Salt Deposit Density). Arester yang sudah berkontaminasi diukur arus bocor yang mengalir pada elemen blok dan pada isolasi arester. Berdasarkan percobaan yang telah dilakukan, kenaikan arus bocor arester pada elemen blok bahwa kenaikan arus bocor untuk tingkat kontaminasi ringan,sedang dan berat naik rata-rata $17.5 \%$ untuk semua tegangan uji. Sementara pada kontaminasi rendah dan sedang arus bocor yang terjadi pada isolasi polimer arester tidak. singnifikan perubahannya,Arus bocor yang dihasilkan linier dengan tingkat kontaminan pada badan arester. Secara jelas dapat disimpulkan bahwa pengaruh kontaminasi sangat signifikan dalam perubahan arus bocor.
\end{abstract}

Kata Kunci : Arester tanpa sela, Arus bocor, Kontaminasi, Penuaan,

\begin{abstract}
Gapless arester leakage current can be used as an indicator to determine the aging level of the arester. Leakage current is influenced by contaminants present in the arester insulation. This paper analyzes the effect of contamination on arester leakage currents as an indicator of arester aging. Contaminants used are calcium carbonate plus kaolin dissolved into water, to determine the level of calcium carbonate contaminants, the ESDD (Equivalent Salt Deposit Density) method is used. Contaminated aresters are measured as leakage currents flowing to the block elements and to the arester insulation. Based on experiments that have been carried out, the increase in leakage current of the arester on the block element that increases the leakage current to the level of light, medium and heavy contamination rises by an average of $17.5 \%$ for the voltage of all test voltages. While at low and moderate contamination the leakage current that occurs in the polymer arester insulation does not significantly change, the leakage current generated is linear with the level of contaminants in the arester body. It can clearly be concluded that the effect of contamination is very significant in changes in leakage currents.
\end{abstract}

Keywords : Gapless arester, Leakage current, Kontamination, Aging,

\section{Pendahuluan}

Tegangan lebih dari awan ke tanah adalah suatu peristiwa alam yang tidak terdeteksi kapan dan dimana terjadinya. Hal ini merupakan ancaman bagi sistim tenaga atau bangunan diatas tanah [1].

Dengan posisi yang terletak di jalur khatulistiwa maka Indonesia merupakan negara beriklim tropis. Curah hujan yang tinggi merupakan ciri-ciri negara beriklim tropis seperti Indonesia dengan hari Guruh sebesar 200 hari guruh/tahun. Curah hujan yang tinggi berdampak pada jumlah hari guruh pertahun yaitu 200 hari guruh per tahunnya. Secara statistik angka ini jauh lebih besar dari pada beberapa negara di dunia seperti
Amerika Serikat 100, Afrika dan Brasil masingmasing 60 dan 40 hari gutruh/tahun [2]. Dengan demikian hari guruh kerapatan petir di Indonesia dapat mencapai $10 \mathrm{sambaran} / \mathrm{km}^{2} /$ tahun [3].

Tanpa peralatan pelindung dari sambaran petir maka sistem tenaga listrik sangat dan mudah terkena sambaran petir. Sistem perlindungan petir sangat dibutuhkan di daerah dengan kerapatan petir yang tinggi. Untuk perlindungan petir umumnya digunakan adalah arester. Arester akan bekerja bila ada tegangan lebih hingga mencapai batas aman peralatan tersebut Tingkat ketahanan Isolasi (BIL). Pada keadaan normal tanpa gangguan arester bersifat sebagai isolator. Walaupun pada keadaan 
normal arester bersifat isolator tetapi arus bocor tetap menggalir dalam orde mikroamper.

Untuk menentukan tingkat penuaan atau degradasi arester maka arus bocor dapat digunakan [4-6]. Arus bocor yang terjadi pada arester merupakan gabungan dari arus bocor dalam akibat elemen blok arrester dan arus bocor luar akibat pengotoran dari isolasi arester. Arus bocor dalam (internal) adalah arus bocor akibat dari penuaan elemen arester dan arus bocor eksternal adalah arus bocor akibat kontaminan yang terjadi pada badan arester. Pada keadaan bersih (tanpa kontaminan) hanya ada arus bocor internal yang mengalir ke tanah, inilah yang mengakibatkan penuaan pada elemen arester. Jika ada kontaminasi pada bodi arester, maka arus bocor adalah kontribusi dari arus bocor akibat penuaan elemen arester dan akibat kontaminasi [7]. Untuk mengetahui seberapa banyak pengaruh arus bocor eksternal terhadap penuaan arester maka kedua arus bocor ini perlu dipisahkan.

Pengaruh kalium karbonat terhadap pengotoran isolasi arester dan hubungan dengan arus bocor dijelaskan secara rinci pada jurnal ini. Arus bocor pada arester terdiri dari arus bocor dalam blok arester dan arus bocor yang terjadi di luar yaitu pada isolasi atau bodi arester itu sendiri. Untuk mengetahui pengaruh kontaminasi pada isolasi arester maka pengukuran arus bocor dilakukan di kedua sumber arus bocor tersebut.

\section{Arester Tanpa Sela}

Arester tanpa sela yaitu jenis arester dengan material non linearnya dominan berupa material Zinc Oxide. Arester jenis ini adalah jenis tanpa sela sehingga yang berperanan menahan arus pada keadaan normal adalah tahanan dari elemen blok arester itu sendiri [8]. Tahanan arester ini akan menjadi sangat kecil ketika terjadi tegangan lebih akibat sambaran petir atau suja hubung. Pada saat itu arester berperan sebagai konduktor yang mengalirkan arus lebih ke tanah. Dan apabila gangguan tegangan lebih berakhir maka fungsi arester akan kembali seperti semula [9].

Kelebihan arester tanpa sela ini bahwa respon yang sangat cepat ketika tegangan lebih terjadi sehingga pembuangan arus lebih ke tanah dapat diatasi secepatnya. Kelemahan arester tanpa sela sangat tergantung pada material dalam arester tersebut. Tahanan dalam arrester blok dan arus bocor mempengaruh suhu pada arrester tersebut. Selain dari itu pengotoran pada isolasi arester juga mempengaruhi kinerja dari arester.

\section{Isolasi Polymer}

Untuk isolasi digunakan material polymeric seperti dalam Gambar1. Material polymeric adalah senyawa non logam yang terbuat dari material organik. Bahan bukan logam mempunyai sifat afinitas yang membagi elektron denan membentuk ikatan kovalen. Ikatan kovalen adalah ikatan antara gabungan dua atau lebih atom yang sama atau berdeda untuk membentuk molekur yang besar atau makro.

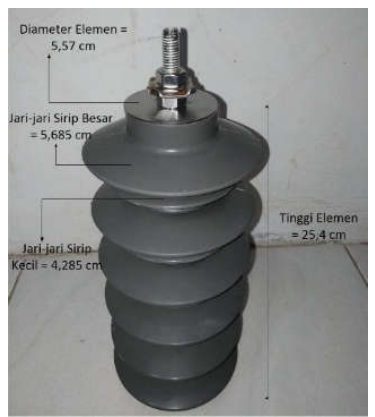

Gambar 1. $\mathrm{ZnO}$ arester dengan isolasi polimer

Material kontaminasi mempunyai massa jenis. Parameter ini menentukan bobot dari material itu sendiri. Massa jenis kecil dalam volume yang sama jauh lebih ringan dari material dengan massa jenis tinggi. Polimer merupakan material dengan massa jenis yang keci sehingga berat polimer lebih ringan dari pada berat material logam. Sifat ini menjadi ciri khas dari material polimer disamping itu juga mempunyai sifat menolak air atau lebih dikenal dengan sifat hydrophobicity atau sifat menolak air (water repellent) [10].

\section{Kontaminasi}

Pengotoran atau kontaminasi di isolasi arester dapat terjadi yang dapat mengakibatkan kenaikan kebocoran arus pada isolasi arester tersebut. Hal ini disebabkan oleh material yang menempel pada lapisan isolasi dan dapat membentuk jalur jalan bagi arus menuju ketanah. Semakin besar arus yang ang mengalir maka bisa dikatakan tahanan isolasi tersebut berkurang. Arus ini akan bertambah sebanding dengan kelembaban yang terjadi. Jika hal ini tidak diatasi, maka jalur jalan arus pada permukaan isolasi semangkin terbentuk dan nilai konduktivitas nya semakin tinggi [11].

Sifat konduktor dari kontaminasi dapat mengalirkan arus listrik ke tanah melalui konduktor pentanahan. Sifat konduktif ini disebabkan oleh kandungan beberapa zat yang bersifat garam seperti natrium klorida $(\mathrm{NaCl})$, 
magnesium klorida $\left(\mathrm{MgCl}_{2}\right)$, kalsium karbonat ( $\left.\mathrm{CaCO}_{3}\right)$, dan natrium sulfat $\left(\mathrm{Na}_{2} \mathrm{SO}_{4}\right)$. Larutan garam ini dapat terurai secara mudah dan bisa mengakibatkan tahanan permukaan pada isolasi polimer berubah karena lapisan ini akan membentuk suatu endapan konduktif pada permukaan arester. Lapisan garam yang tidak mudah larut akan mempengaruhi tahanan permukaan lebih kecil dibandingkan dengan lapisan garam yang mudah larut. Beberapa komponen konduktif pada daerah industri dapat larut membentuk larutan asam yang bersifat konduktif, seperti gas $\mathrm{SO}_{2}$, yang dapat membentuk $\mathrm{H}_{2} \mathrm{SO}_{4}$. Tabel 1 adalah pengaruh area terhadap nilai ESDD menurut standar IEC. 815

Tabel 1 Pengaruh area terhadap nilai ESDD menurut standar IEC 815.

\begin{tabular}{|c|c|c|}
\hline $\begin{array}{l}\text { Tingkat } \\
\text { Polusi }\end{array}$ & Area Daerah & $\begin{array}{c}\text { ESDD } \\
\left(\mathrm{mg} / \mathrm{cm}^{2}\right)\end{array}$ \\
\hline Kurang & $\begin{array}{l}\text { - Daerah industri dan } \\
\text { pemukiman penduduk } \\
\text { dengan tempat pembakaran } \\
\text { rendah. } \\
\text { - Derah pertanian, pupuk } \\
\text { dapat meningkatkan polusi } \\
\text { dan pegunungan. } \\
\text { - Daerah dengan jarak } \\
\text { kurang lebih } 10 \mathrm{~km} \text { dari } \\
\text { laut } \\
\text { - Derah dengan ketinggian } \\
\text { antara } 10 \text { sampai } 20 \mathrm{~km} \\
\text { dari laut tanpa angin secara } \\
\text { langsung. }\end{array}$ & $0.03-0.06$ \\
\hline $\begin{array}{c}\text { Menenga } \\
\mathrm{h}\end{array}$ & $\begin{array}{l}\text { - Daerah industri tanpa } \\
\text { polusi gas. } \\
\text { - Daerah dan kawasan } \\
\text { industri kepadatan tinggi } \\
\text { dengan angin . } \\
\text { - Daerah yang berjarak kra- } \\
\text { kira tidak terlalu jauh dari } \\
\text { pantai. }\end{array}$ & $0.06-0.1$ \\
\hline Lebih & $\begin{array}{l}\text { - Daerah dekat dengan laut } \\
\text { dan berangin } \\
\text { - Daerah industri dan } \\
\text { perkotaan dengan tingkat } \\
\text { pembakaran tinggi } \\
\text { - Daerah padang pasir tanpa } \\
\text { hujan yang berlangsung } \\
\text { lama }\end{array}$ & $>0.1$ \\
\hline
\end{tabular}

\section{Arus Bocor}

Apabila tegangan yang harus ditahan sebuah arester melebihi dari kemampuan arester maka akan terjadi aliran arus yang disebut dengan arus bocor. Timbul arus bocor diawali oleh lapisan konduktif pada permukaan badan arrester [12]. Lapisan konduktif terbentuk akibat adanya senyawa garam dan bahan tak larut diudara terutama di daerah pantai, akan terbawa angin dan menempel pada permukaan badan arester.

Pada keadaan bersih, permukaan arester memiliki tahanan listrik yang besar [13]. Pembentukan lapisan konduktif disebabkan karena kontaminasi pada permukaan badan arester sehingga menyebabkan penurunan nilai tahanan pada permukaan arester. Penurunan ini menyebabkan terjadi arus bocor pada permukaan arester. Representasi model sederhana arus bocor arester dapat dilihat pada Gambar 2.

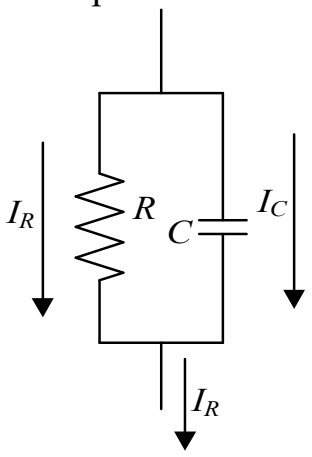

Gambar 2 Pemodelan arus bocor total, resistif dan kapasitif [4].

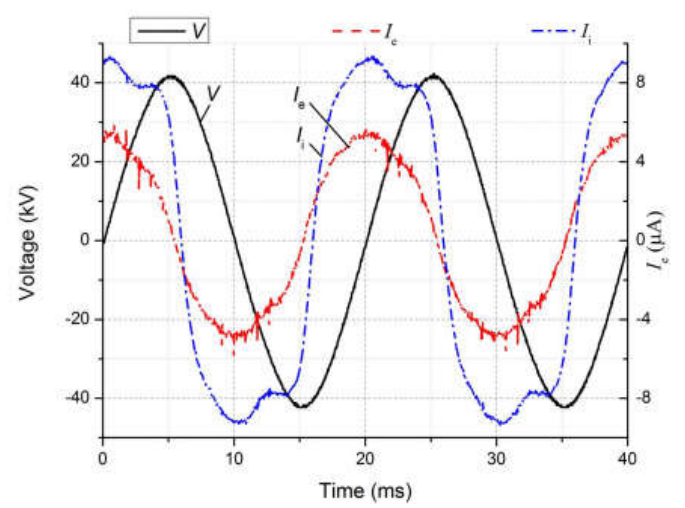

Gambar 3 Arus total dan kapasitif dari arus bocor arester [4].

Arus kapasitor $\left(I_{C}\right)$ dan arus tahanan $\left(I_{R}\right)$ berbanding lurus terhadap nilai komponen $R$ dan $C$ tersebut [14]. Komponen resitif dari arus bocor tersebut bertanggung jawab terhadap tingkat penuaan dari arester blok [15]. Bentuk gelombang arus dapat dilihat Gambar 3. 


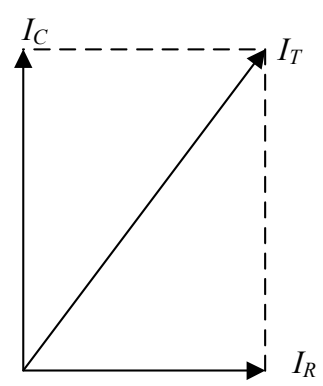

Gambar 4 Diagram vektor dari $I_{T}, I_{R}$ dan $I_{C}$

Fungsi arus dan waktu dari arester blok tersebut dapat dilihat pada persamaan dibawah ini. Sementara $I_{T}, I_{R}$ dan $I_{C}$ bisa ditulis sebagai berikut: [6].

$$
I_{T}(t)=I_{R}(t)+I_{C}(t)
$$

sementara

$$
I_{R}(t)=I_{T}(t)-I_{C}(t)
$$

Dengan keterangan :

$$
\begin{aligned}
& I_{T}(t)=\text { Arus bocor total arester } \\
& I_{R}(t)= \text { Arus bocor komponen resistif } \\
& \text { arester } \\
& I_{C}(t)= \begin{array}{l}
\text { Arus bocor komponen kapasitif } \\
\text { arester }
\end{array}
\end{aligned}
$$

Komponen arus resistif dapat diperoleh dengan mengurangi komponen arus kapasitif dari total kebocoran arus [16]. Seperti yang digambarkan pada vektor diagram pada Gambar 4.

\section{Metodologi}

Dalam penelitian ini keseluruhan proses yang dilakukan dijelaskan dengan gambar berupa diagram alir penelitian agar mudah di pahami. Selanjutnya setiap proses yang ditampilkan dalam diagram alir tersebut dijelaskan satu persatu.

Gambar 5 menampilkan diagram alir dari alur penelitian yang akan dilakukan pada penelitian ini. Diagram alir penelitian ini pat dilihat pada Gambar 5 dibawah ini. Secara singkat dapat dijelaskan bahwa sebelum arester diuji dengan memberikan tegangan tinggi sesuai dengan skenario percobaan, maka arester diberi kontaminasi terlebih dahulu sesuai dengan tingkat pengotoran.

Tingkat kontaminasi atau pengotoran dibuat secara manual dengan mencampurkan beberapa unsur-unsur kimia. Campuran dibuat sedemikian rupa dengan kadar dan proses yang sesuai sehingga diperoleh larutan yang dapat digunakan sebagai larutan pengotoran.
Untuk jenis kontaminasi ringan dibuat dengan cara mencampur 40 gr Kaolin dan 100 gr Kalium karbonat $\left(\mathrm{CaCO}_{3}\right)$ dengan 6 liter air bersih. Agar kontaminan dapa menempel pada bodi arester maka arester direndam kedalam larutan polutan tersebut dan dibiarkan selama 10 menit. Setelah itu arester diangkat kemudian dikeringkan selama \pm 24 jam dalam suatu ruangan untuk pengeringan.

Untuk tingkat pengotoran sedang 6 liter air dicampur dengan $40 \mathrm{gr}$ kaolin dan $500 \mathrm{gr} \mathrm{CaCO}_{3}$. Agar kontaminan dapa menempel pada bodi arester maka arester direndam kedalam larutan polutan tersebut dan dibiarkan selama 10 menit. Setelah itu arester diangkat kemudian dikeringkan selama \pm 24 jam dalam suatu ruangan untuk pengeringan.

Kemudian untuk jenis pengotoran lebih berat dibuat dengan cara menambahkan 40gr Kaolin dan $900 \mathrm{gr}$ Kalsium karbonat ke dalam 6 liter air. Untuk menempelkan kontamina pada bodi arester sama seperti proese sebelumnya yaitu dengan proses yang sama dicelupkan kedalam polutan dan dibiarkan selama 10 menit kemudian dikeringkan selama \pm 24 jam dalam suatu ruangan.

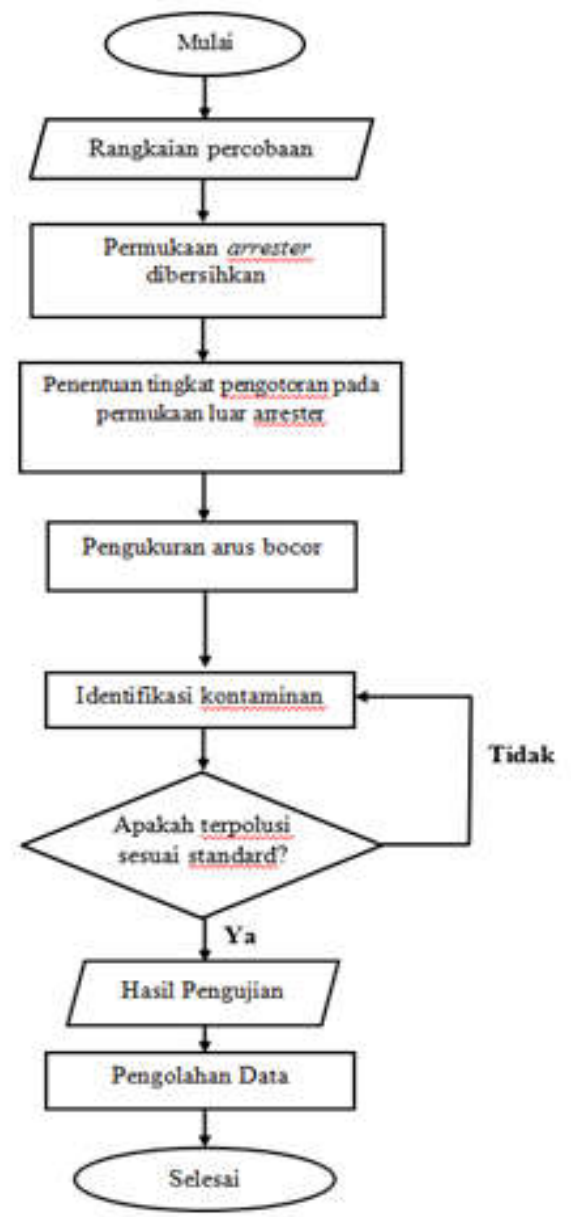

Gambar 5 Digram alir penelitian 
Rangkain percobaan untuk menentukan arus bocor arester dapat dilihat pada Gambar 6. Arester dihubungkan dengan rangkaian pembangkitaukn tegangan tinggi bolak balik. Tegangan yang diinputkan ke arester diukur mengunakan pembagi kapasitor dan hasilnya di lihat pada channel 1 osiloskop dan arus bocor diperoleh dengan menempatkan tahanan sebesar $1 \mathrm{k} \Omega$ pada kedua terminal pentanahan arester. Arus bocor dari arester blok ditampilkan pada channel 2 dan arus bocor dari isolasi polimer pada channel 3 osiloskop.

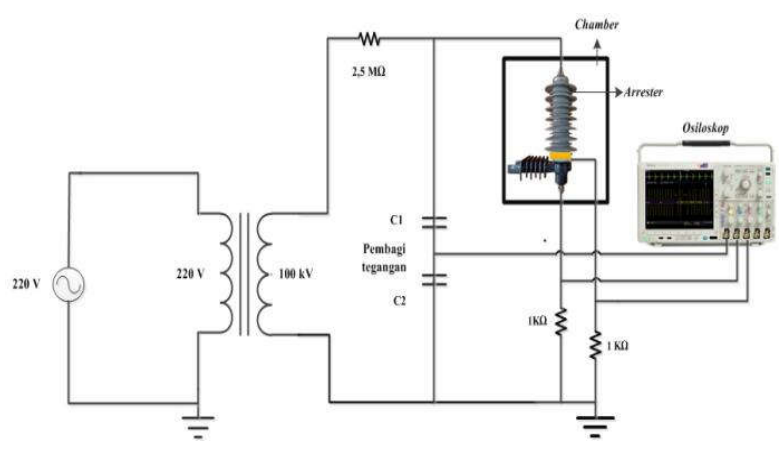

Gambar 6 Rangkaian percobaan

Tabel 2 Arus bocor internal dan eksternal arester isolasi polimer

\begin{tabular}{|c|c|c|c|c|c|c|}
\hline \multirow{2}{*}{$\begin{array}{c}\text { Tegangan } \\
\text { Uji }(\mathrm{kV})\end{array}$} & \multicolumn{3}{|c|}{ Arus bocor dalam blok $(\mu \mathrm{A})$} & \multicolumn{3}{c|}{ Arus bocor pada isolasi $(\mu \mathrm{A})$} \\
\cline { 2 - 7 } & Ringan & Sedang & Berat & Ringan & Sedang & Berat \\
\hline 14 & 213.3 & 279.9 & 334.7 & 2.2 & 2.6 & 4.5 \\
\hline 18 & 289.4 & 354.2 & 423.6 & 2.9 & 3.3 & 6.4 \\
\hline 20 & 312.2 & 387.9 & 454.8 & 3.4 & 3.6 & 7.5 \\
\hline 22 & 379.4 & 420.2 & 489.2 & 3.8 & 4.2 & 8.6 \\
\hline 24 & 405.7 & 445.3 & 521.7 & 4.6 & 4.8 & 9.8 \\
\hline
\end{tabular}

\section{Hasil Penelitian}

Tingkat kontaminan ringan, sedang, dan berat dapat dilihat pada Gambar 7 dibawah ini:

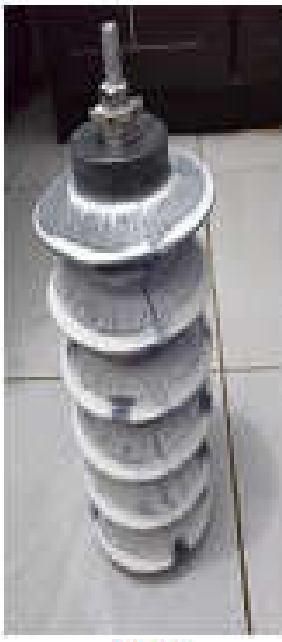

(a)

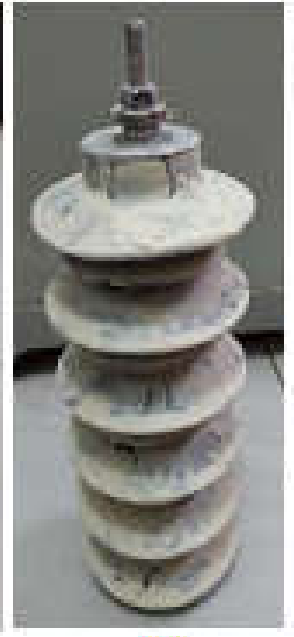

(b)

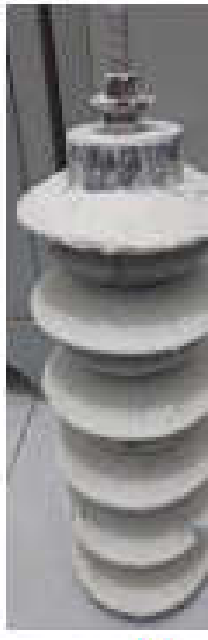

(c)
Gambar 7 Tingkat kontaminasi arester, (a) ringan (b) sedang dan (c) berat.

Gambar 7 menampilkan hasil dari proses pengotoran yang terdapat pada bodi arester setelah diberi kontaminasi. Gambar 7 (a) mengambarkan tingkat kontaminasi rendah dimana kontaninan hanya menempel pada ujung isolator. Selanjutnya gambar 7 (b) dan (c) adalah hasil dari proses pengotoran bodi arester untuk tingkat sedang dan berat.

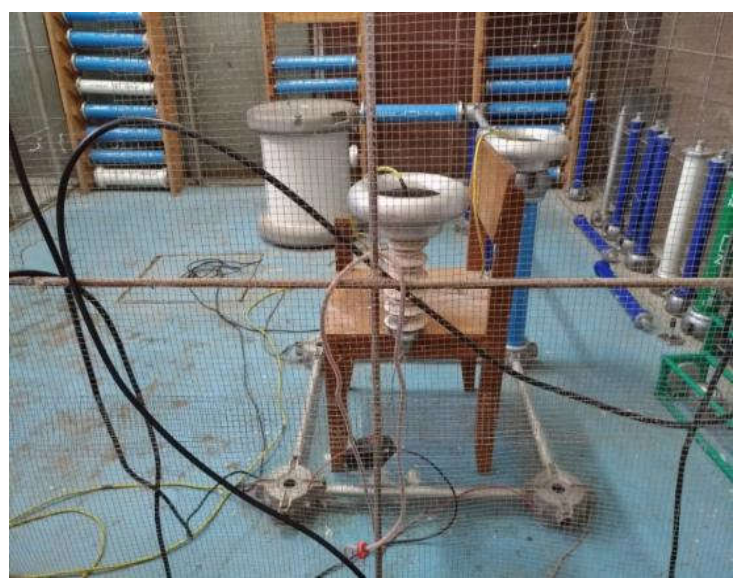

Gambar 8 Pengujian polymer arester tanpa sela

Regulator tegangan befungsi untuk mengatur tegangan keluaran pada transformator. Trafo tegangan tinggi $100 \mathrm{kV}$ ini berfungsi untuk menghasilkan tegangan tinggi yang akan 
diterapkan pada arester. Sementara resistor $40 \mathrm{k} \Omega$, digunakan untuk melindungi trafo dari tegangan yang cukup besar. Kapasitor digunakan sebagai penyearah dari tegangan tinggi $\mathrm{AC}$ ke tegangan tinggi DC dan meredam dengung dari tegangan AC. Dan untuk mengukur tegangan tinggi

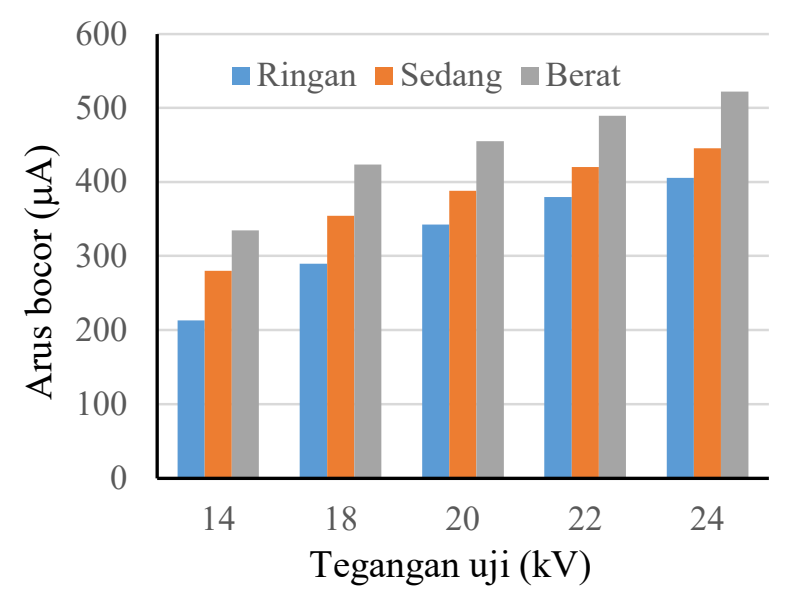

Gambar 9. Diagram batang arus bocor internal

Gambar 9 dan gambar 10 adalah diagram batang arus bocor yang terjadi didalam blok dan di isolasi arester. Kondisi kontaminasi rendah,sedang dan berat diuji untuk masing masing tegangan 14,18 , 20,22 , dan $24 \mathrm{kV}$.

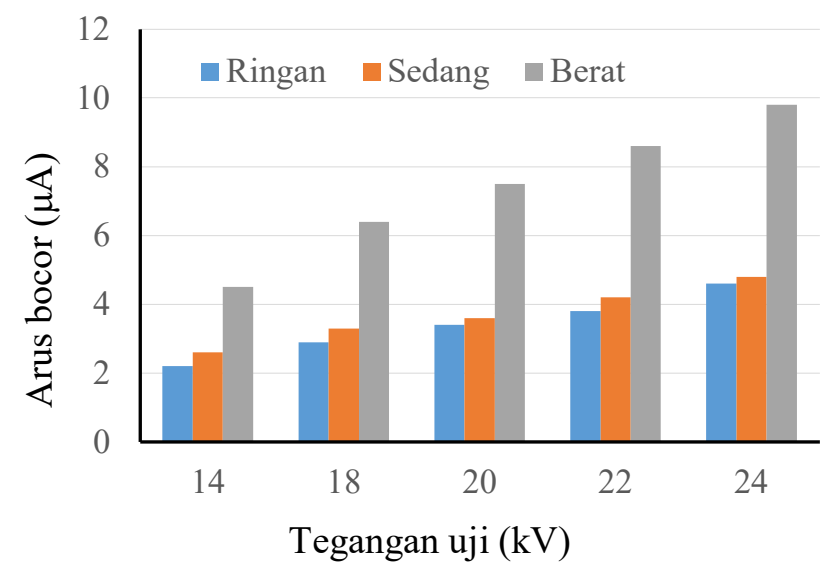

Gambar 10. Diagram batang arus bocor eksternal

\section{Analisa}

Gambar 9 adalah grafik arus bocor pada blok arester untuk kondisi kontaminasi ringan sedang dan berat. Arus bocor yang terjadi di dalam blok arester blok dipengaruhi oleh kontaminasi dari luar. Dapat dilihat pada grafik Gambar 10 bahwa kenaikan arus bocor untuk tingkat kontaminasi ringan,sedang dan berat naik rata-rata $17.5 \%$ untuk digunakan pembagi kapasitif dengan rasio 1:450. Sebagai sensor arus bocor digunakan resistor sebear $1 \mathrm{k} \Omega$.yang dihubungkan ke osiloskop. Tabel 2 adalah hasil pengukuran arus bocor internal dan eksternal arester isolasi polimer.

tegangan semua tegangan uji. Hal ini disebabkan oleh panas yang dihasilkan akibat stress tegangan sinusoidal pada arester tidak dapat dilepas secara sempurna melalui isolasi polimer karena ditutupi oleh kontaminasi. Panas yang tidak dapat dibuang keluar tersebut akan mengakibatkan kenaikan suhu dalam blok arester sehingga arus bocor dari dalam blok arester menjadi tinggi.

Gambar 10 adalah grafik arus bocor yang terjadi pada isolasi polimer arester. Dari gambar 10 jelas terlihat bahwa kontaminasi pada isolasi polimer arester sangat mempengaruhi arus bocor yang terjadi. Antara kontaminasi rendah dan sedang arus bocor yang terjadi tidak terlalu singnifikan perubahannya, tetapi pada kontaminasi berat arus bocor yang terjadi naik menjadi dua kali lipat pada tegangan uji 18 sapai dengan $24 \mathrm{kV}$. Hal ini menunjukan bahwa kontaminasi yang terjadi pada isolasi polimer menjadi media untuk mengalirnya arus bocor ke tanah.

\section{Kesimpulan}

Dari hasil ini dapat disimpulkan bahwa arus bocor yang terjadi pada arester berupa arus bocor internal dan eksternal. Pengaruh kontaminasi sangat signifikan dalam perubahan besar arus bocor ekternal dan dapat mempengaruhi perkiraan umur arester. Untuk mengetahui arus bocor yang terjadi pada elemen blok arester maka pengaruh arus bocor dari isolasi ini perlu dipishakan. Arus bocor yang terjadi pada elemen blok arester adalah arus bocor dikurangi dengan arus bocor yang terjadi pada isolasi polimer. Dengan penelitian yang akurat dapat dinyakan persentasi kontribusi arus bocor isolasi sehingga dapat ditentukan faktor koresi dalam menentukan umur dari arester denga mengukur arus bocor keseluruhan.

\section{Acknowledment}

Terima kasih kepada Jurusan Teknik Elektro Universitas Andalas yang telah membantu pembiayaan penelitian ini melalui skema hibah penelitian jurusan dengan nomor kontrak 091/UN16.09.D/PL/2019. 


\section{Daftar Pustaka}

[1]. T. Gunawan, Pandiangan, L. N. L, "Analisis Tingkat Kerawanan Bahaya Sambaran Petir dengan Metode Simple Additive Weighting," 2014

[2]. H. T. R.D. Purianto, dan Widiastuti, A.N, "Perbandingan Tegangan Residu Arester SiC dan $\mathrm{ZnO}$ Terhadap Variasi Front Time," vol. 2.0, p. 8, 2016.

[3]. L. A. I.E Wibowo, dan M. T. Prasetyo, "Evaluasi Perlindungan Gardu Induk $150 \mathrm{kV}$ Pandean Lamper di Trafo III 60 MVA Terhadap Gangguan Surja Petir," 2012.

[4]. N. P. Gesang, T.Haryono, dan Suharyanto, "Karakteristik Tegangan Arus Arester Bocor SiC Pada Suhu dan Kelembapan Berbeda," 2014.

[5]. D. I. S. d. S. Handoko, "Pemakaian dan Pemeliharaan Arester Pada Gardu Induk 150 kV Srondol PT. Pln (Persero) P3B JB Region Jawa Tengah dan DIY UPT Semarang," 2012.

[6]. Novizon. Z. Abdul-Malek, dan Aulia,, "A New Method to Extract the Resistive Component of the Metal Oxide Surge Arester Leakage Current," 2008.

[7]. Y.D. Dhimas, "Pengaruh Penambahan $\mathrm{CuO}$ Terhadap Karakteristik Elektrik Pada Keramik Varistor $\mathrm{ZnO}$ Dengan Suhu Penyinteran 13000 C," 2010.

[8]. Z.A.-Malek, Novizon, Nouruddeen Bashir, dan Aulia, "Condition Monitoring of Zinc Oxide Surge Aresters," 2011.

[9]. A. Syakur, "Pengaruh Kelembaban dan Suhu Terhadap Karakteristik Arus Bocor Pada Isolator Bahan Resin Epoksi dengan Pengisi Bahan Pasir Silika," 2015.

[10]. P. Wahyu, "Analisis Dan Upaya Pengurangan Efek Harmonisa Pada Generator Set (Genset) Dengan Penambahan Beban Non Linier," Tugas Akhir, 2014

[11]. S. Asep Andang, "Unjuk Kerja Permukaan Isolator Pasangan Luar Polimer Epoxy Resin $20 \mathrm{kV}$ pada Berbagai Kondisi Lingkungan," 2005.

[12]. D. Y. T. Purba, "Pengaruh Temperatur Terhadap Tegangan Lewat Denyar AC Pada Isolator Piring Terkontaminasi Polutan," Tugas Akhir, vol. Teknik Elektro USU, 2016.
Novizon, "Field experience on surgearrester condition monitoring - Modified Shifted Current Method," in 45th International Universities Power Engineering Conference UPEC2010, 2010, pp. 1-5.

[14]. Z. Abdul-Malek, N. Yusoff, and M. F. M. Yousof, "Performance analysis of modified shifted current method for surge arrester condition monitoring," in 2010 International Conference on High Voltage Engineering and Application, 2010, pp. 649-652.

[15]. P. M. De Oliveira-De Jesus, "A New Method to Determine Incremental Costs of Transmission Lightning Protection Systems," Electric Power Components and Systems, vol. 47, pp. 1759-1774, 2019/12/14 2019.

[16]. G. Dobric, Z. Stojanovic, and Z. Stojkovic, "MOSA monitoring using unsynchronised measurements of voltage and leakage current," in Mediterranean Conference on Power Generation, Transmission, Distribution and Energy Conversion (MedPower 2016), 2016, pp. 1-5.

[13]. Z. Abdul-Malek, N. Yusoff, and M. F. M. 